\title{
Functional Biodiversity and Farming Techniques:How to Measure Impacts?
}

C.A. Costa

Escola Superior Agrária de Viseu/IPV

Quinta da Alagoa, Estrada de Nelas

3500-606 Viseu

Portugal

S. Duarte

Laboratório Nacional de Engenharia Civil

Av. Brasil 101, 1700-066 Lisboa

Portugal

E. Figueiredo and A. Mexia

CEER, Instituto Superior de Agronomia/UTL

Tapada da Ajuda, 1349-017 Lisboa

Portugal

\author{
M.C. Godinho \\ Escola Superior Agrária de Santarém/IPS \\ Quinta do Galinheiro, Santarém \\ Portugal \\ C. Mateus \\ Instituto Nacional de Recursos Biológicos \\ Quinta do Marquês \\ Av. da República, 2784-505 Oeiras \\ Portugal
}

Keywords: technical profiles, IPM, organic farming, ecological infrastructures

\begin{abstract}
Farming and environment are key issues on political and social agendas on a global scale. In the past two decades, agricultural systems went through a major revision having in mind ecological and landscape concepts on a conservation basis. Technical profiles (TP) are used as study tools to evaluate operational costs and to assess the deviation between theoretical production models and each farm system. TPs of sustainable crop systems such as integrated production and organic farming are based on principles, tasks and technologies, such as crop protection, cover crops and ecological infrastructures preservation, that expectably induce differences in the functional biodiversity present in each system. The main target of the present work was to develop a methodology to measure the impact(s) of farming practices on pest importance (occurrence and damages) and functional biodiversity. This study was carried out during 2005 and 2006 and was supported by the national project AGRO 545 "The environmental indicators to assess the IPM, the integration production, the organic farming and the sustainable use of pesticides". A survey was performed with 191 vineyard farmers in the four Portuguese main important regions: Verdes, Douro, Dão and Alentejo. The survey was carried out during the crop season and biodiversity was assessed (pests and beneficial arthropods) simultaneously. The results presented here are related to a preliminary data analysis. As expected, IPM and organic farming impact on the environment tends to be low, but conventional systems revealed a similar tendency, induced by the need of reducing production costs. Differences among regions were also found, as expected, due to territorial structure and farm dimensions. In monitored vineyards, $48.2 \%$ of species variance was explained by the studied variables. The number of discontinuities in the surroundings was found to be associated to all arthropod functional groups.
\end{abstract}

\section{INTRODUCTION}

Functional biodiversity is an important component in sustainable plant protection schemes on vineyards. The knowledge about species present, their dynamics and the pesticide side effects is crucial for the success of biological control based on conservation. In parallel, the food availability for the beneficials (disposal of pollen and nectar, alternative hosts/preys), refuges and habitat manipulation for the biodiversity preservation is an important part of the technical profiles of modern agricultural systems. Biodiversity maintenance and enhancement represents one of the environmental goals and is integrated 
in an interdependent and multiple interaction schemes, including water quality, soil fertility, etc.

At the present time, in Europe, agricultural policies fixed agri-environment schemes (AES). The AES payments provide opportunities to invest a lot of money into biodiversity conservation and enhancement and, at the same time, take into account socioeconomic factors, compensating farmers for loss of income or additional costs of applying alternative farming practices to maintain an ecologically sustainable agriculture.

It is necessary, however, to evaluate the AES effectiveness, as the considerable costs for taxpayers require adequate justification.

Recent EU-projects (EASY (http://www.dow.wau.nl/natcons/NP/EASY/) and BioAssess (http://www.nbu.ac.uk/bioassess/) showed that the issue of design and targeting of agri-environmental programmes is crucial since not all AES have been successful (Feehana et al., 2005).

A recent study in southern England carried out in the context of the EASY project, assessed the impacts of an agri-environment field margin prescription on farmland biodiversity. There were positive impacts on diversity or abundance on flora, bees and grasshoppers. No effects on birds were observed or bird territories, spiders or carabid beetles but also no negative impacts. The results confirmed that there are benefits to farmland biodiversity from introducing new grassland habitat at the edges of arable fields, though their effects vary between taxa and species and are dependent on landscape structure (Clough et al., 2005; Burgio and Sommaggio, 2007; Clough et al., 2007; Concepción et al., 2008; Georgianne et al., 2008; Flynn et al., 2009; Roth et al., 2008).

According to some proposals from net working groups in Europe, it is desirable to know more about ecosystem functioning. There is a need to find and show more functionality of biodiversity (identification of key elements and key processes) and need to evaluate the complete management system (Biala et al., 2006).

In this circumstance and with the major goal of assessing the impact(s) of farming practices on pest importance (occurrence and damages) and functional biodiversity, a survey was carried out on Portuguese vineyards, supported by the national project AGRO 545. Data related with technical profiles (TP) and biodiversity were collected.

\section{MATERIAL AND METHODS}

We apply a biodiversity assessment approach from a comparison among conventional agriculture (CA), integrated pest management (IPM) and organic farming (OF) systems, located in 4 vineyard important regions: Alentejo (27 vineyards), Dão (31), Douro (32) and Verdes (29). Data were collected from 109 vineyards in 2006. A survey was performed to achieve technical profiles on the 3 afore-mentioned production systems. In each farm, biodiversity was assessed (arthropods and weeds).

Arthropods were captured using the beating technique, from 10 to 21 July 2006. In each vineyard, ten vines were chosen at random and, in each vine, twelve beat trays were made (a total of 120 beatings/vineyard). Arthropods dislodged fell onto a canvas beat tray $\left(45 \times 64 \mathrm{~cm}\right.$; surface area $\left.\sim 0.30 \mathrm{~m}^{2}\right)$, killed with ether in the vineyard and identified in the laboratory. First, arthropods were separated by orders, except the hemipterans that were identified by suborders (Auchenorrhyncha+Sternorryncha and Heteroptera); afterwards, heteropterans and coleopterans were identified up to family level. Each taxon was catalogued by their trophic functional role based on literature review (Imms et al., 1977; Dolling, 1988; Wilson, 1988; Booth et al., 1990; Mockford, 1993; Fauvel, 1999; Marc et al., 1999; Stelzl and Devetak, 1999): phytophagous, predators, parasitoids, mycophagous and detritivores.

Weeds were assessed using a protocol based on a aleatory transept of 300 steps. In each 30 steps the closest weed was identified to species level.

Data collected were divided in four main groups:

1) vineyard characterization (production system, vineyard age, area, plant density, surrounding coefficient (total of crops/species in margins, all occurrences registered, whether new or repeated), different crops/species surrounding (number of different 
crops/species in margins, each one registered just once, even if detected more than once), discontinuities (presence of physic infrastructures that causes discontinuities), surrounding factor - based on the sum of surrounding coefficient (coefficient 0.2) and different crops/species surrounding (coefficient 0.4), divided by the number of discontinuities (coefficient 0.4), surrounding factor/area, average annual production). For example, when margins are orchard - carrots - orchard, surrounding coefficient was 3 and different crop/species coefficient was 2 ;

2) cultural practices (irrigation, cover cropping, herbicide applications, fertilizations, interrow vegetation coverage, soil coverage);

3) pesticides (treatments, number of interventions, active substances);

4) weeds (genus/species).

Possible differences in arthropod communities' structure among vineyards were analyzed with multivariate techniques. A redundancy analysis (RDA) was performed using log transformed data and based on fields versus arthropods data matrices. A forward selection procedure was performed to determine which explanatory variables had a significant relationship with arthropods data. Statistical significance of the canonical axes was evaluated by Monte Carlo permutation test $(\mathrm{p}<0.05)$. Multivariate statistical procedures were performed in CANOCO 4.0 software (Ter Braak and Smilauer, 2002).

\section{RESULTS AND DISCUSSION}

A total of 1215 arthropods were captured, belonging to the groups: Araneae, Coleoptera, Dermaptera, Diptera, Hemiptera, Hymenoptera, Lepidoptera, Neuroptera, Orthoptera, Psocoptera and Thysanoptera.

For weeds 6028 specimens were identified, that represent 24 species or genus, distributed in 11 families: Amaranthaceae, Boraginaceae, Cyperaceae, Compositae, Convolvulaceae, Cruciferae, Equisetaceae, Scrophulariaceae, Fumariaceae, Geraniaceae and Poaceae.

\section{Vineyard Characterization}

In monitored vineyards, $20.5 \%$ of species variance was explained by variables associated with vineyards characterization. Forward selection results showed that "Alentejo region" $(\mathrm{F}=5.88 ; \mathrm{P}=0.002)$, "discontinuities" $(\mathrm{F}=5.07 ; \mathrm{P}=0.014)$ and "CA" $(\mathrm{F}=3.41 ; \mathrm{P}=0.030)$ were significant. "Alentejo region" and "discontinuities" were responsible for approximately $5.0 \%$ of species variance and "CA" vineyards for $2.0 \%$ (Fig. 1). In "Alentejo region" and in "CA" vineyards, functional groups were less represented. The number of "discontinuities" was positively associated to "phytophagous", "parasitoids" and "predators".

\section{Cultural Practices}

In monitored vineyards, $6.5 \%$ of species variance was explained by variables associated with cultural practices. Forward selection results were only significant for $\mathrm{p}<0.10$ for "cover cropping" $(\mathrm{F}=2.44 ; \mathrm{P}=0.078)$, being responsible for $2.0 \%$ of species variance (Fig. 2).

The variable cover cropping is suggested to be associated with "predators", "parasitoids" and "detritivores", by the RDA biplot.

\section{Pesticides}

In monitored vineyards, $3.1 \%$ of species variance was explained by variables associated with pesticides. Forward selection results did not show any significant variable (Fig. 3).

\section{Weeds}

In monitored vineyards, $25.1 \%$ of species variance was explained by variables associated with weeds. Forward selection results showed that Raphanus raphanistrum $(\mathrm{F}=4.99 ; \quad \mathrm{P}=0.010)$, Amaranthus retroflexus $(\mathrm{F}=2.67 ; \mathrm{P}=0.034)$ were considered 
significant, being responsible for 4.0 and $2.0 \%$ of species variance respectively (Fig. 4).

"Phytophagous" are suggested to be associated with $R$. raphanistrum, while "predators", "parasitoids" and "detritivores" are suggested to be associated with A. retroflexus.

\section{All Variables}

In monitored vineyards, $48.2 \%$ of species variance was explained by the studied variables. Forward selection results indicated that "Alentejo region" $(\mathrm{F}=5.88 ; \mathrm{P}=0.002)$, "discontinuities" $(\mathrm{F}=5.07 ; \mathrm{P}=0.014)$ " "CA" vineyards $(\mathrm{F}=3.41 ; \mathrm{P}=0.030)$ and "different crop/species surrounding" $(\mathrm{F}=2.46 ; \mathrm{P}=0.044)$ were considered significant, being responsible for $5.0 \%$ of species variance for "Alentejo region" and "discontinuities", and $2.0 \%$ of species variance for "CA" and "different crop/species surrounding". Echium plantagineum $(\mathrm{F}=2.74 ; \mathrm{P}=0.060)$, "Douro region" $(\mathrm{F}=2.55 ; \mathrm{P}=0.070)$, "active ingredients" $(\mathrm{F}=2.50 ; \quad \mathrm{P}=0.080)$ and Raphanus raphanistrum $(\mathrm{F}=2.21 ; \mathrm{P}=0.092)$ although not considered significant for $\mathrm{p}<0.05$, would be significant for $\mathrm{p}<0.10$, being "Douro region", "active ingredients" and E. plantagineum responsible for 3.0, 2.0 and $1 \%$ of species variance, respectively (Fig. 5).

"Alentejo region" was characterized by the low number of arthropods captured. "Predators" are suggested to be negatively associated to CA vineyards. "Parasitoids" and also other functional groups are suggested to be positively associated to "discontinuities".

In Alentejo region functional groups were less represented, in arthropods and weeds, probably related to extensive systems and larger farms (farm structure based on farms with a average dimensions of $66 \mathrm{ha}$ ), especially if compared with Dão, Douro and Verdes where the farm dimension is considerably small $(5,4 \mathrm{ha})$ (INE, 2007). When the production system adopts cover cropping as well as when the discontinuities are higher, it was possible to find a positive association with phytophagous, parasitoids and predators, which will be an indicator of more sustainable farming systems.

Parasitoids and also other functional groups are suggested to be positively associated to discontinuities created by ecological infrastructures as well as diversifying farm activities, more common on OF and IPM systems.

As expected, IPM and organic farming impact on the environment tends to be low, but conventional systems revealed a similar tendency, induced by the need of reducing production costs.

\section{ACKNOWLEDGEMENTS}

The authors wish to thank the growers, which kindly allowed us to conduct our work in their orchards and vineyards; APAS, AAPIM, PAINHO, AJAP, ADVID, AVITILIMA, APIDÃO, AGROBIO, ATEVA, SOGRAPE and BIOCOA for technical assistance. This work was financed by the project AGRO 545 "The environmental indicators to assess the IPM, integrated production, organic farming and sustainable use of pesticides".

\section{Literature Cited}

Biala, K., Paracchini, M.L., Terres, J.-M., Pointereau, P. and Pezet. J. 2006 Biodiversity serving agriculture. Proc. Summer School 'Biodiversity Serving Agriculture', Report EUR 22550, Inst Environment and Sustainability, Ranco, Italy, 3-6 July 2006.

Booth, R.G., Cox, M.L. and Madge, R.B. 1990. Guides to Insects of Importance to Man: No.3. Coleoptera. Intl Inst. Entomology, British Natural Hist. Museum. London, UK.

Burgio, G. and Sommaggio, D. 2007. Syrphids as landscape bioindicators in Italian agroecosystems. Agri. Ecosystems and Environment 120(2-4):416-422.

Clough, Y., Kruess, A. and Tscharntke, T. 2007. Organic versus conventional arable farming systems: functional grouping helps understand staphylinid response. Agr. Ecosystems and Environment 118(1-4):285-290.

Clough, Y., Kruess, A., Kleijn, D. and Tscharntke, T. 2005. Spider diversity in cereal fields: comparing factors at local, landscape and regional scales. J. Biogeography 
32(11):2007-2014.

Concepción, E.D., Díaz, M. and Baquero, R.A. 2008. Effects of landscape complexity on the ecological effectiveness of agri-environment schemes. Landscape Ecology 23(2):135-148.

Dolling, W.R. 1988. Guide to the Heteroptera. $10^{\text {th }}$ International Course on Applied Taxonomy of Insects and Mites of Agricultural Importance. Intl. Inst. Entomology, British Natural History Museum. London, UK.

Fauvel, G. 1999. Diversity of Heteroptera in agroecosystems: role of sustainability and bioindication. Agri. Ecosystems and Environment 74(1-3):275-303.

Feehana, J., Desmond, A. and Gillmorb, N. 2005. Effects of an agri-environment scheme on farmland biodiversity in Ireland. Agri. Ecosystems and Environment 107(2-3):275286.

Flynn, D.F.B., Gogol-Prokurat, M., Nogeire, T., Molinari, N., Trautman, B., Richers, B.B., Simpson, N., Mayfield, M.M. and DeClerck, F. 2009. Loss of functional diversity under land use intensification across multiple taxa. Ecology Letters 12(1):2233.

Georgianne, J.K.G., Holland, J.M., Bailey, A. and Thomas, M.B. 2008. Efficacy and economics of shelter habitats for conservation biological control. Biological Control 45(2):200-209.

Imms, A.D., Richards, O.W. and Davies, R.G. 1977. Imms' General Textbook of Entomology, Volume 2 - Classification and Biology. Chapman \& Hall, London, UK.

INE. 2007. Inquérito às Estruturas das Explorações Agrícolas. Instituto Nacional de Estatística, Lisboa.

Marc, P., Canard, A. and Ysnel, F. 1999. Spiders (Araneae) useful for pest limitation and bioindication. Agri. Ecosystems and Environment 74(1-3):229-273.

Mockford, E.L. 1993. North American Psocoptera (Insecta) - Flora \& Fauna Handbook The Sandhill Crane Press, Gainesville, USA.

Roth, T.A.V., Peter, B. and Weber, D. 2008. A Swiss agri-environment scheme effectively enhances species richness for some taxa over time. Agri. Ecosystems and Environment 125(1-4):167-172.

Stelzl, M. and Devetak, D. 1999. Neuroptera in agricultural systems. Agri. Ecosystems and Environment 74(1-3):305-321.

Ter Braak, C.J.F. and Smilauer, P. 2002. CANOCO reference manual and user's guide to Canoco for Windows: software for canonical community ordination (version 4.5). Microcomputer Power. Ithaca, New York.

Wilson, M.R. 1988. Homoptera: Auchenorrhyncha. $10^{\text {th }}$ International Course on Applied Taxonomy of Insects and Mites of Agricultural Importance. CAB International Institute of Entomology and British Natural History Museum. London, UK. 


\section{\& $\quad \underline{\text { Tables }}$}

Table 1. Arthropods captured by groups and regions.

\begin{tabular}{|c|c|c|c|c|c|c|c|}
\hline Region & Production system & & Phytophagous & Parasitoids & Predators & Mycophagous & Detritivores \\
\hline \multirow{6}{*}{ Alentejo } & \multirow{2}{*}{$\mathrm{OF}(\mathrm{n}=4)$} & $\mathrm{N}$ & 15 & & 15 & 1 & \\
\hline & & Mean \pm SE & $3.75 \pm 6.50$ & & $3.75 \pm 2.49$ & $0.25 \pm 0.43$ & \\
\hline & \multirow{2}{*}{ IPM (n=17) } & $\mathrm{N}$ & 24 & 5 & 36 & & 2 \\
\hline & & Mean \pm SE & $1.41 \pm 1.33$ & $0.29 \pm 0.57$ & $2.12 \pm 2.30$ & & $0.12 \pm 0.47$ \\
\hline & \multirow{2}{*}{$\mathrm{CA}(\mathrm{n}=5)$} & $\mathrm{N}$ & 4 & 1 & 4 & & \\
\hline & & Mean \pm SE & $0.80 \pm 1.17$ & $0.20 \pm 0.40$ & $0.80 \pm 1.17$ & & \\
\hline \multirow{5}{*}{ Dão } & $\mathrm{OF}(\mathrm{n}=0)$ & $\begin{array}{c}\mathrm{N} \\
\text { Mean } \pm \text { SE }\end{array}$ & & & & & \\
\hline & \multirow[b]{2}{*}{ IPM (n=16) } & $\mathrm{N}$ & 205 & 27 & 205 & 4 & 8 \\
\hline & & Mean \pm SE & $12.81 \pm 24.15$ & $1.69 \pm 2.87$ & $12.81 \pm 16.54$ & $0.25 \pm 0.56$ & $0.50 \pm 0.94$ \\
\hline & \multirow{2}{*}{$\mathrm{CA}(\mathrm{n}=14)$} & $\mathrm{N}$ & 41 & 11 & 55 & 2 & 2 \\
\hline & & $\operatorname{Mean} \pm \mathrm{SE}$ & $2.93 \pm 3.43$ & $0.78 \pm 1.08$ & $3.93 \pm 4.22$ & $0.14 \pm 0.52$ & $0.14 \pm 0.35$ \\
\hline \multirow{6}{*}{ Douro } & \multirow{2}{*}{$\mathrm{OF}(\mathrm{n}=5)$} & $\mathrm{N}$ & 5 & 5 & 23 & & \\
\hline & & Mean \pm SE & $1.00 \pm 1.26$ & $1.00 \pm 1.55$ & $4.60 \pm 3.61$ & & \\
\hline & \multirow{2}{*}{ IPM (n=10) } & $\mathrm{N}$ & 13 & 2 & 43 & & 1 \\
\hline & & Mean \pm SE & $1.30 \pm 0.90$ & $0.20 \pm 0.60$ & $4.30 \pm 5.68$ & & $0.10 \pm 0.30$ \\
\hline & \multirow{2}{*}{$\mathrm{CA}(\mathrm{n}=11)$} & $\mathrm{N}$ & 56 & 5 & 91 & 1 & 1 \\
\hline & & Mean \pm SE & $5.09 \pm 5.07$ & $0.45 \pm 0.78$ & $8.27 \pm 6.97$ & $0.09 \pm 0.29$ & $0.09 \pm 0.29$ \\
\hline \multirow{5}{*}{ Verdes } & $\mathrm{OF}(\mathrm{n}=0)$ & $\begin{array}{c}\mathrm{N} \\
\text { Mean } \pm \text { SE }\end{array}$ & & & & & \\
\hline & \multirow{2}{*}{ IPM (n=15) } & $\mathrm{N}$ & 47 & 57 & 96 & 2 & 7 \\
\hline & & Mean \pm SE & $3.13 \pm 3.26$ & $3.80 \pm 11.31$ & $6.40 \pm 6.88$ & $0.13 \pm 0.34$ & $0.46 \pm 0.72$ \\
\hline & \multirow{2}{*}{$\mathrm{CA}(\mathrm{n}=12)$} & $\mathrm{N}$ & 46 & 6 & 34 & 2 & 5 \\
\hline & & Mean \pm SE & $3.83 \pm 6.45$ & $0.50 \pm 1.12$ & $2.83 \pm 3.62$ & $0.17 \pm 0.55$ & $0.41 \pm 0.95$ \\
\hline \multirow{2}{*}{\multicolumn{2}{|c|}{ Total $(\mathrm{n}=112)$}} & $\mathrm{N}$ & 456 & 119 & 602 & 12 & 26 \\
\hline & & Mean \pm SE & $4.18 \pm 44.16$ & $1.09 \pm 12.08$ & $5.52 \pm 57.25$ & $0.11 \pm 1.19$ & $0.24 \pm 2.52$ \\
\hline
\end{tabular}




\section{Figures}



Fig. 1. RDA biplots for vineyards in Alentejo, Dão, Douro and Verdes regions relatively to significant variables associated with vineyard characterization $(\mathrm{p}<0.05)$ after forward selection (Alentejo region, discontinuities, CA).

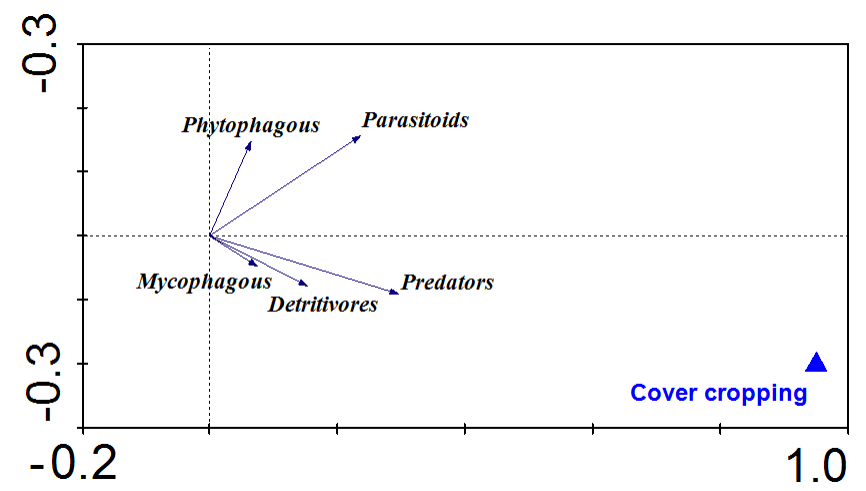

Fig. 2. RDA biplots for vineyards in Alentejo, Dão, Douro and Verdes regions relatively to significant variables associated with vineyard characterization $(\mathrm{p}<0.10)$ after forward selection (cover cropping).

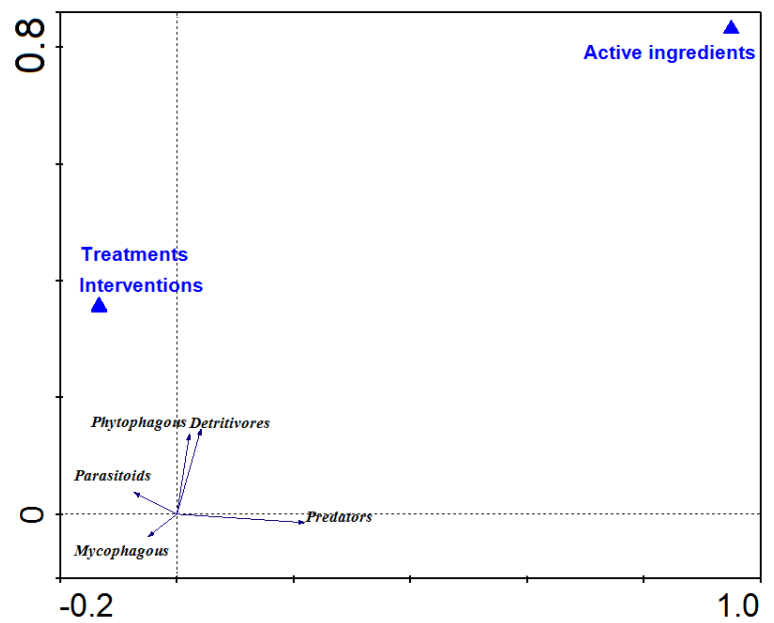

Fig. 3. RDA biplots for vineyards in Alentejo, Dão, Douro and Verdes regions relatively to variables associated with pesticides (number of interventions, total number of treatments, total load of pesticides in 2006). 


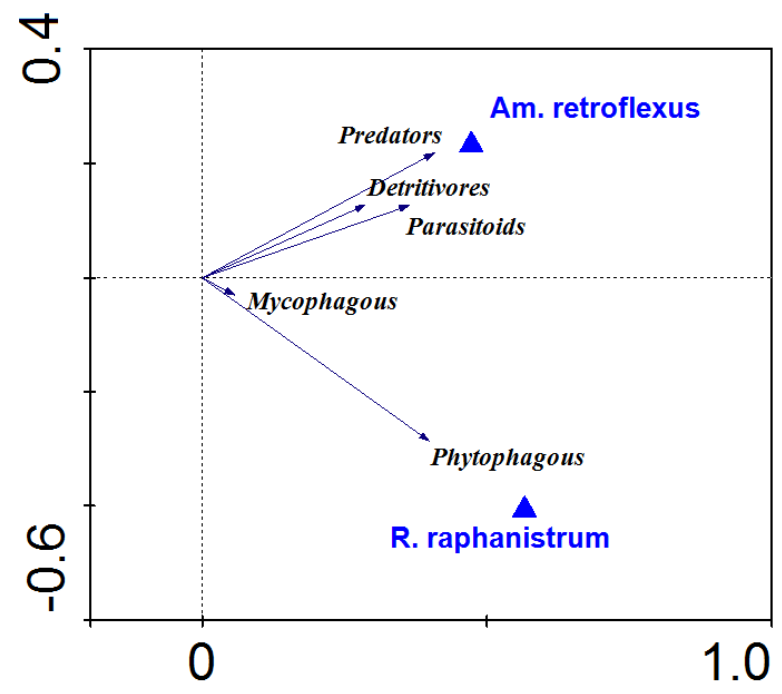

Fig. 4. RDA biplots for vineyards in Alentejo, Dão, Douro and Verdes regions relatively to variables associated with weeds (Raphanus raphanistrum, Amaranthus retroflexus).



Fig. 5. RDA biplots for vineyards in Alentejo, Dão, Douro and Verdes regions relatively to significant variables $(p<0.05)$ after forward selection (Alentejo region, discontinuities, CA vineyards and different crop/species in the surrounding environment). 